\title{
Pancreatic endosonography: Clinical TNM staging compared to histology
}

TL TIO, MD, PHD

ABSTRACT: Endosonography has been reported to be effective in the staging of gastrointestinal carcinoma. Pancreatic carcinoma is included in the new (1987) TNM classification. Resectability is abandoned in favour of depth of tumour invasion. In the author's preoperative study, endosonography was accurate for staging of tumour categories, and early stages of disease could be distinguished from advanced carcinomas. The presence or absence of regional lymph nodes can be detected. Tissue diagnosis by biopsy and endosonographyguided cytology is now possible. This imaging technique will become the standard procedure for the staging of pancreatic carcinoma. Can J Gastroenterol $1990 ; 4(9): 572-575$

Key Words: Endosonography, Histology, Pancreatic carcinoma, TNM staging

\section{L'endosonographie pancréatique: La classification TNM clinique comparée à l'histologie}

RESUME: On a rapporté l'efficacité de l'endosonographie dans la classification des cancers gastro-intestinaux. Le cancer du pancréas relève maintenant de la nouvelle classification TNM (1987). La résécabilité a été abandonnée et fait place à la profondeur de l'invasion tumorale. Dans notre étude préopératoire, l'endosonographie a permis la classification exacte des catégories de tumeurs; elle a également aidé à distinguer les cancers aux premiers stades de leur évolution, des cancers avancés. La présence ou l'absence d'extension aux ganglions lymphatiques a été décelée. Le diagnostic portant sur les tissus prélevés par cytoponction à l'aiguille échoguidée est désormais possible. Cette technique d'imagerie deviendra la procédure standard dans la classification des cancers du pancréas.

\footnotetext{
$\mathrm{C}$
} ONVENTIONAL ABDOMINAL ultrasound is a standard imaging technique for evaluation of patients with pancreatic diseases. This procedure, however, is often hampered by the presence of bowel gas and adipose tissue. Endoscopic retrograde cholangio- pancreatography (ERCP) is accurate for the detection and staging of pancreatobiliary abnormalities. Endoscopic ultrasonography, generally known as endosonography, was developed to improve sonographic images by direct approach to the target of

Academic Medical Center, Department of Gastroenterology-Hepatology, Amsterdam, The Netherlands

Correspondence and reprints: Dr TL Tio, Academic Medical Center, Department of Gastroenterology-Hepatology, Meibergdreef 9, 1105 AZ Amsterdam, The Netherlands. Telephone 020-566-9111. Fax 020-566-4440

interest via the gastrointestinal lumen (1-9). Recently, staging of pancreatic carcinoma has been included in the new (1987) TNM classification $(10,11)$. In a prospective study, endosonography was performed preoperatively to assess the accuracy and limitations of endosonography in the TNM staging of pancreatic and ampullary carcinoma.

\section{INSTRUMENTS}

For pancreas endosonography the author has been using Olympus echoendoscopes EU-M2 and EU-M3. The latter emits a switchable frequency of 7.5 or $12 \mathrm{MHz}$ and a biopsy channel for endosonography-guided cytology or biopsy or videoechoendoscope (VU. M2) (Figure 1). Recently, a small catheter echoprobe which can be introduced into the biopsy channel of a forward-viewing large calibre gastroscope became available (Figure 2 ). The specifications of these instruments are summarized in Table 1.

\section{INVESTIGATION TECHNIQUES}

The transgastric approach allows clear imaging of the body and tail of the pancreas because of the topographic anatomical relationship between the stomach and pancreas (Figure 3). For examination of the entire head of the pancreas, a transduodenal approach is usually necessary. The configuration of the stomach plays a crucial role for imaging of the pancreas. A long extended 


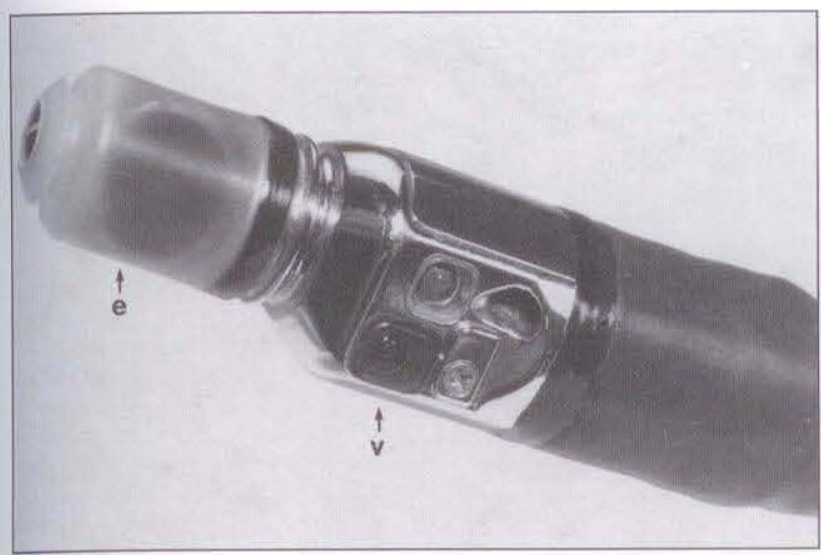

Figure 1) An Olympus prototype videoechoendoscope (VU-M2) with a small echoprobe (e) attached at the tip of a side-viewing duodenoscope (v). Note the smaller diameter of the echoprobe compared to the gastroscope

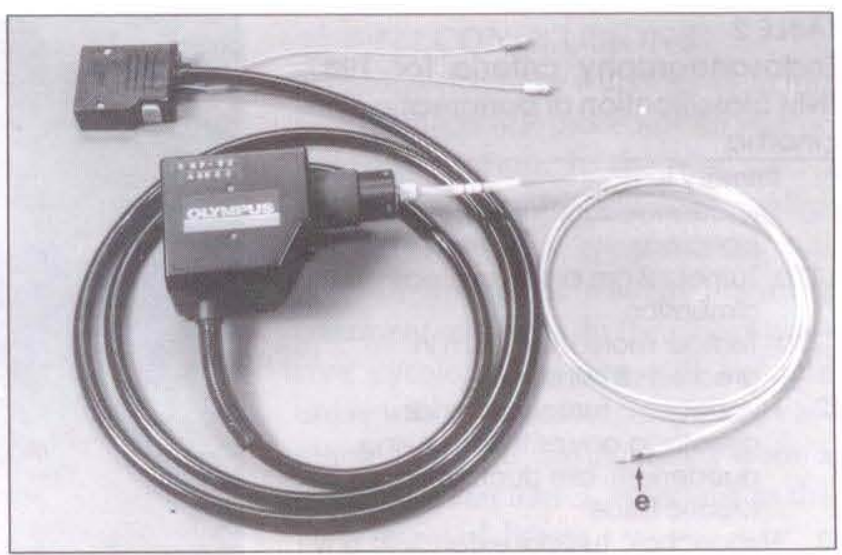

Figure 2) An Olympus prototype catheter echoprobe (e), which can be introduced through the instrumental channel of a large calibre gastroscope

\section{TABLE 1}

\section{Technical data of various Olympus echoendoscopes}

\begin{tabular}{lcccc}
\hline Echoendoscope & EU-M2 & EU-M3 & VU-M2 (video) & Catheter echoprobe \\
\hline Endoscope & Side-viewing & Side-viewing & Side-viewing & GIF-IT10/GIF-IT20 \\
Echoprobe length & $42 \mathrm{~mm}$ & $42 \mathrm{~mm}$ & $44 \mathrm{~mm}$ & $140 \mathrm{~cm}$ (catheter) \\
Diameter & $13 \mathrm{~mm}$ & $13 \mathrm{~mm}$ & $10.4 \mathrm{~mm}$ & $3 \mathrm{~mm}$ \\
Frequency & $7.5 \mathrm{or} 10 \mathrm{MHz}$ & $7.5 \mathrm{MHz} / 12 \mathrm{MHz}$ & $7.5 \mathrm{MHz}$ & $7 \mathrm{MHz}$ \\
Depth of penetration & $10 \mathrm{~cm}$ & $10 \mathrm{~cm} / 3 \mathrm{~cm}$ & $10 \mathrm{~cm}$ & $3 \mathrm{~cm}$ \\
Axial resolution & $0.2 \mathrm{~mm}$ & $0.2 \mathrm{~mm} / 0.12 \mathrm{~mm}$ & $0.2 \mathrm{~mm}$ & $-0.2-0.3$ \\
\hline
\end{tabular}

The catheter echoprobe is radial scanning, while all echoendoscopes are mechanical radial scanning $\left(180^{\circ}\right.$ or $\left.360^{\circ}\right)$. Only the EU-M3 has capability for endoultrasonography-guided puncture or biopsy. "Switchable frequency

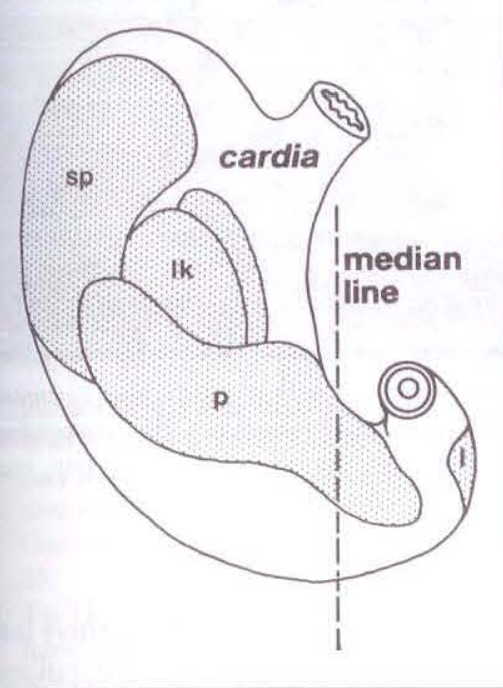

Figure 3) Anatomic scheme (posterior view) shows the relationship between the stomach and the surrounding organs. sp Spleen; lk Left kidney; P Pancreas; I Liver

stomach provides clear imaging of the entire pancreas. In the case of stomach after partial resection (Billroth 1 or II), adequate imaging of the pancreas is difficult or impossible. Patients after a

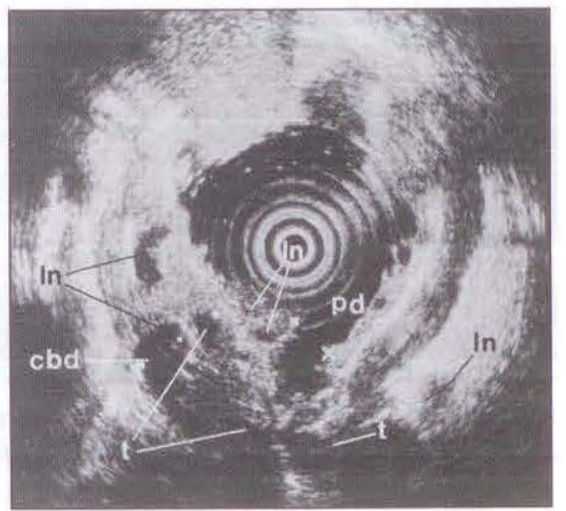

Figure 4) Endosonogram of a hypoechoic pancreatic carcinoma $(t)$ obstructing the common bile duct (cbd) and pancreatic duct ( $p d)$, a 'double duct lesion.' In Lymphnodes suspected of metastases

total gastrectomy should not undergo endosonography because the pancreas cannot be visualized sonographically.

The most important landmark for a transgastric approach is the splenic vein, which is localized dorsally adjacent to the body and tail of the pancreas. The entire splenic vein can be followed from the splenoportal con- fluence to the splenic hilum. By the transduodenal approach, the head of the pancreas is imaged between the duodenal wall and the mesenteric vessels. Cross-sectional images analogous to computed tomography should be made for standardization of endosonography images.

\section{INTERPRETATION OF ENDOSONOGRAPHIC IMAGES}

The interpretation of pancreatic carcinoma is comparable to transcutaneous ultrasonography. For classifying ductular abnormalities, criteria used for the interpretation of ERCP must be incorporated. A pancreatic carcinoma is imaged as a hypoechoic tumour usually obstructing the main Wirsung duct associated with a prestenotic dilatation of the pancreatic and common bile ducts. Thus, the cause and extent of the 'double duct lesion' can be imaged (Figure 4). Occasionally intraductal tumours originating from the wall of the pancreatic duct can be found. The intraductal polypoid pat- 
TABLE 2

Endosonography criteria for 1987 TNM classification of pancreatic carcinoma

T Primary fumour

T1 Hypoechoic tumour limited to the pancreas

Tla Tumour $2 \mathrm{~cm}$ or less in greatest dimension

Tlb Tumour more than $2 \mathrm{~cm}$ in greatest dimension

T2 Hypoechoic fumour extends directly to any of the following: duodenum, bile duct, peripancreatic tissue

T3 Hypoechoic tumour extends to any of the following: stomach, spleen, colon, adjacent large vessels

Tx Primary tumour cannot be assessed

N Regional lymph nodes

NO No regional lymph node metastasis

N1 Regional lymph node metastasis

$\mathrm{Nx}$ Regional lymph nodes cannot be assessed

M Distant metastases

MO No distant metastases

M1 Distant metastases: Hepatic metastasis, peritoneal dissemination

Mx Distant metastases cannot be assessed

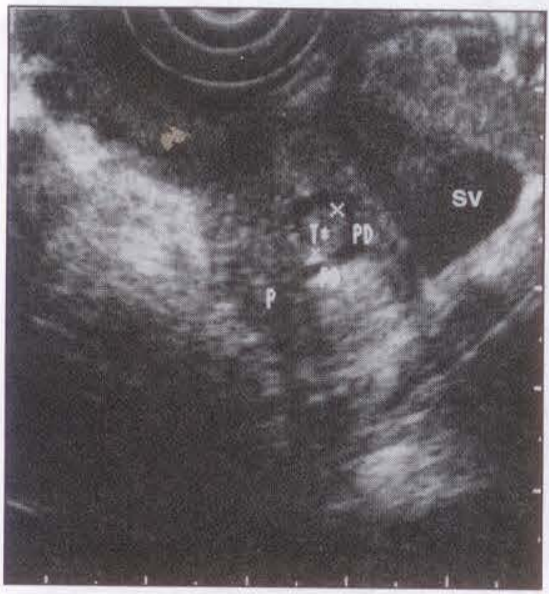

Figure 5) Endosonogram of an early pancreatic carcinoma $(T)$ extended into the dilated pancreatic duct (PD). P Pancreas; SV Splenic vein

tern may represent proliferation of the epithelium of the pancreatic duct or the carcinoma itself. Recently, pancreatic carcinoma was incorporated into the new (1987) TNM classification (Table 2).

Staging of distant metastases, however, should be excluded due to the limited penetration depth of ultrasound. Therefore, liver metastases and peritoneal dissemination may not be imaged.
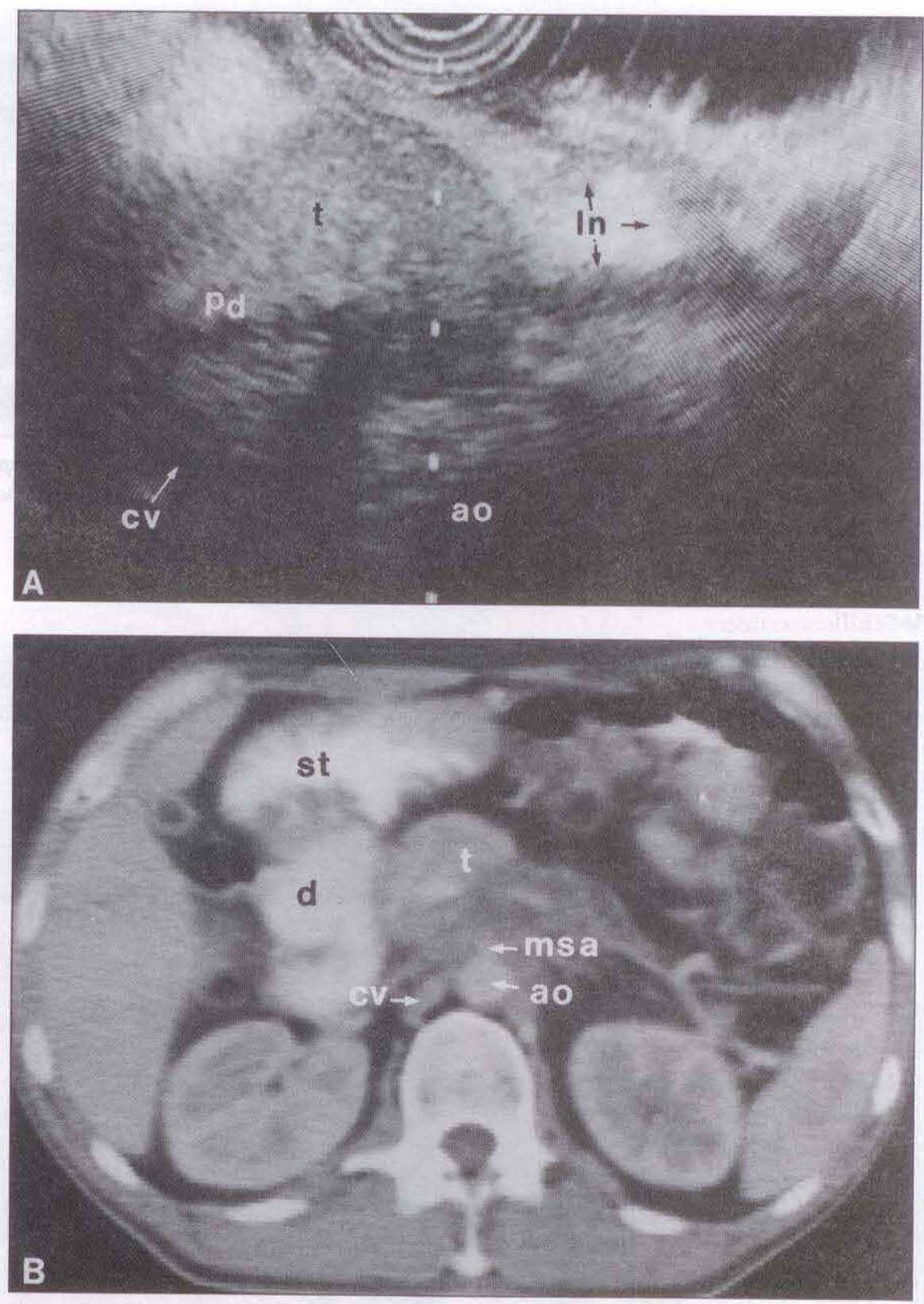

Figure 6) A Endosonogram of extensive pancreatic carcinoma $(t)$ with retroperitoneal extension adjacent to the aorta (ao). cv Caval vein; In Lymph nodes suspected of metastases. B Corresponding computed tomography shows a tumour mass $(t)$ extending to the aorta $(a o)$. cv Caval vein; msa Mesenteric superior artery; st Stomach; d Duodenum

CLINICAL TNM STAGING

Pancreatic head carcinoma usually causes obstruction of the common bile duct. Thus, obstructive jaundice is the most common clinical symptom. The prognosis, however, remains poor despite advantages of diagnostic modalities (12-14). The size and extent of pancreatic carcinoma may play an important role in the prognosis $(15,16)$. In contrast, obstructive jaundice due to carcinoma of the body and/or tail of the pancreas is rare except when there is a very extensive tumour mass. Ampullary carcinomas, however, may cause obstructive jaundice even in the early stage of disease (17). The new (1987) TNM classification should be used for staging carcinomas of the head of the pancreas. Therefore, the common bile duct and duodenum are used as demarcation marks for T2 carcinoma. Early carcinomas are therefore more frequently expected to be found in the 
junction between the head and body of the pancreas, or a distance from the common bile duct without symptoms of jaundice, eg, uncinate process. Infiltration into the stomach is classified as a T3 carcinoma. Moreover, infiltration into the adjacent major blood vessels (splenic vein, portal vein, splenoportal confluence, mesenteric vessels, etc) can be clearly imaged because of the realtime character of ultrasound and the ability to position the echoprobe towards the target of interest.

Occasionally, portal hypertension with the presence of gastric varices because of splenic or portal obstruction can be found, which is usually a contraindication for tumour resection. Early pancreatic carcinoma is defined as a Tl carcinoma (diameter less than 2 $\mathrm{cm}$ ) with no evidence of lymph node involvement. Such small carcinomas are rare and can be found incidentally during evaluation of patients with abdominal discomfort (Figure 5). In patients with obstructive jaundice, the stage of pancreatic carcinoma is usually

\section{REFERENCES}

1. Tio TL, Tytgat GNJ. Endoscopic ultrasonography in the assessment of intra- and transmural infiltration of tumours in the esophagus, stomach and papilla of Vater and in the detection of extra-esophageal lesion. Endoscopy 1984:4:220-5.

2. Tio TL, Tytgat GNJ. Endoscopic ultrasonography in staging local resectability of pancreatic and periampul. lary malignancy. Scand J Gastroenterol 1986;21(Suppl 123):135-42.

3. Tio TL, Tytgar GNJ. Endoscopic ultrasonography in analysing periintestinal lymph node abnormality. Preliminary results of studies in vitro and in vivo with histology. Scand J

Gastroenterol 1986;21(Suppl 123):15863.

4. Tio TL, Tytgat GNJ. Atlas of Transintestinal Ultrasonography. Aalsmeer: Mur-Kostverloren, 1986.

5. Tio TL. Endosonography in Gastroenterology. Heidelberg, Berlin, New York, London, Tokyo: Springer Verlag, 1988.

6. Yasuda K, Mukai H, Cho E, Nakayima M, Kawai K. The use of endoscopic ultrasonography in the detecting and staging of carcinoma of the papilla of already advanced. In the author's clinical experience of more than five years, the incidence of lymph node involvement in $\mathrm{Tl}$ carcinoma is approximately $40 \%$ (9). This has also been reported elsewhere (14), and may reflect the highly malignant nature of disease $(13,14)$. The incidence of lymph node metastasis increases with the depth of tumour infiltration. In contrast, the incidence in $\mathrm{Tl}$ ampullary carcinoma was $0 \%(9)$.

The accuracy rate of endosonography in diagnosing regional lymph nodes and distant metastases is comparable with that of esophagogastric carcinoma $(18,19)$. Endosonography is more accurate in diagnosing metastatic involvement than nonmetastatic lymph nodes. This is of utmost importance from the clinical point of view because of the poor prognosis of the disease. For the assessment of liver metastasis, transcutaneous sonography is necessary to assess metastases in the right liver lobes and to confirm diagnosis by cytological puncture.

Vater. Endoscopy 1988;20:218-22.

7. Yasuda K, Mukai H, Fujimoto S, Nakayima M, Kawai K. The diagnosis of pancreatic cancer by endoscopic ultrasonography. Gastrointest Endosc 1988;34:1-8.

8. Tio TL, Tytgat GN]. Endoscopic ultrasonography of normal and pathologic upper gastrointestinal wall structure: Comparison of studies in vitro with histology. Scand J Gastroenterol 1986;21(Suppl 123):27-33.

9. Tio TL, Tytgat GNJ, Cikot RJLM, Houthoff H]. Ampullopancreatic carcinomas: TNM staging with endosonography. Radiology. (In press)

10. Hermanek P, Sobin LH. TNM Classification of Malignant Tumours. International Union Against Cancer, 4th edn. Berlin, Heidelberg, New York, London, Paris, Tokyo: Springer Verlag, 1987.

11. Sobin LH, Hermanek P, Hutter RP. TNM classification of malignant tumors. Cancer 1988; 61:2310-4.

12. Cancer Facts and Figures 1987, New York. Am Cancer Soc 1987:14.

13. Moossa AR. Pancreatic cancer: Approach to diagnosing, selection for surgery and choice of operation. Cancer 1982;50:2689-98.

\section{CONCLUSIONS}

Endosonography will become an important diagnostic procedure for staging pancreatic cancer. In the near future, tissue diagnosis by endosonographyguided cytology of lymph nodes will play an important role in planning treatment strategies. In the case of positive cytology, surgery will become unfavorable. Moreover, ampullary carcinoma can be distinguished from a pancreatic carcinoma, especially in the early stages of disease.

The clinical role of endosonography in the detection of early pancreatic carcinomas in a nonselected population is still unknown. At present, introduction of endosonography as a screening diagnostic modality appears to be utopic because of the invasive nature of the procedure and the cost-benefit ratio. Endosonography will become the imaging technique of choice for staging pancreatic carcinomas because of its ability to discriminate early stage carcinomas from advanced stages of disease.

14. Cubilla AL, Fortner J, Fitzgerald J. Lymph node involvement in carcinoma of the head of the pancreas area. Cancer 1978;41:880-7.

15. Tsuchiya R, Oribe T, Noda T. Size of the tumor and other factors influencing prognosis of carcinoma of the head of the pancreas. Am J Gastroenterol 1985;80:459-62.

16. Tsuchiya R, Noda T, Harada N, et al. Collective review of small carcinomas of the pancreas. Ann Surg 1986;203:77-81.

17. Makipour H, Cooperman A, Danzi JT, Farmer RG. Carcinoma of the ampulla of Vater: Review of 38 cases with emphasis of treatment and prognostic factors. Ann Surg 1976;183:341-4.

18. Tio TL, Cohen P, Coene PP, Udding J, den Hartog Jager FCA, R Tytgat GNJ. Endosonography and computed tomography of esophageal carcinoma: Preoperative classification compared to the new (1987) TNM classification. Gastroenterology 1989;96:1478-86.

19. Tio TL, Coene PPLO, Schouwink $\mathrm{MH}$, Tytgat GNJ. Esophagogastric carcinoma: Preoperative TNM classification with endosonography, Radiology $1989 ; 173: 411-7$ 


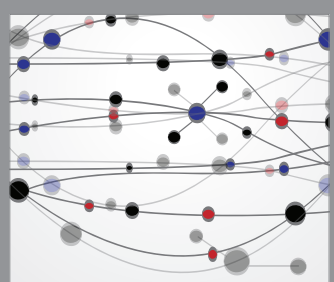

The Scientific World Journal
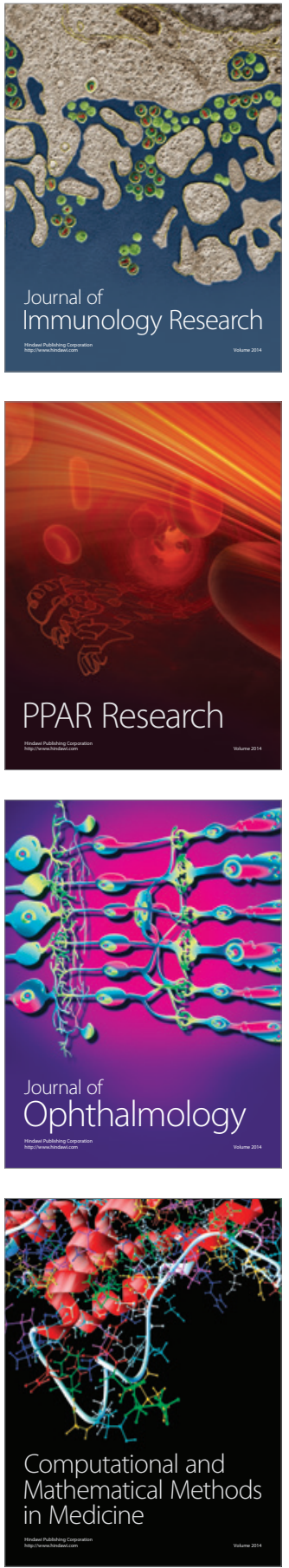

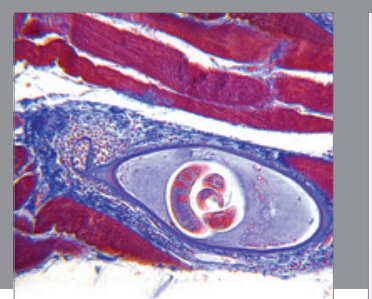

Gastroenterology Research and Practice

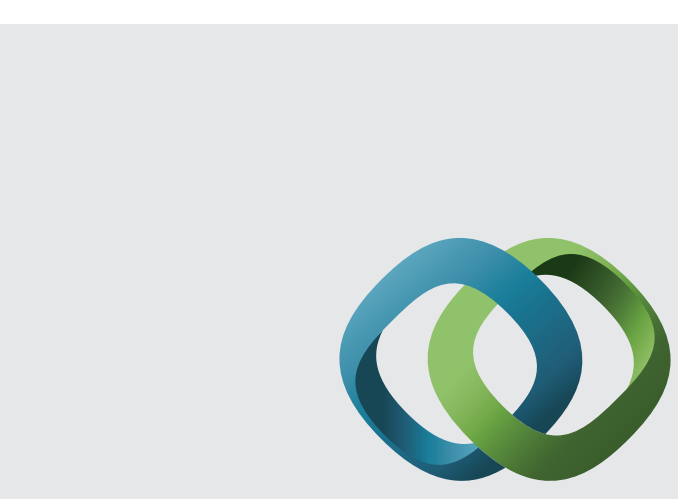

\section{Hindawi}

Submit your manuscripts at

http://www.hindawi.com
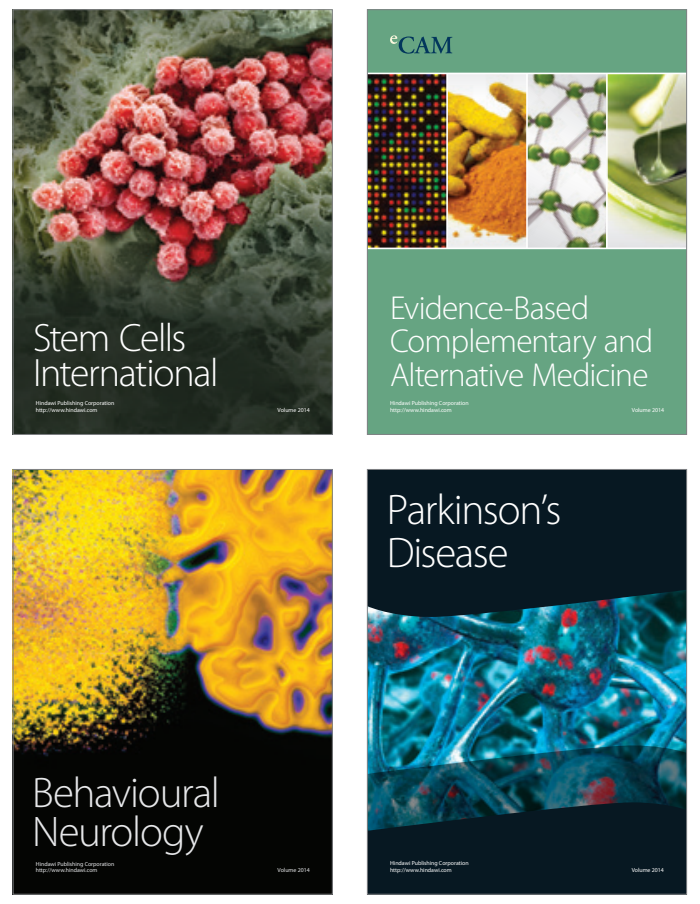
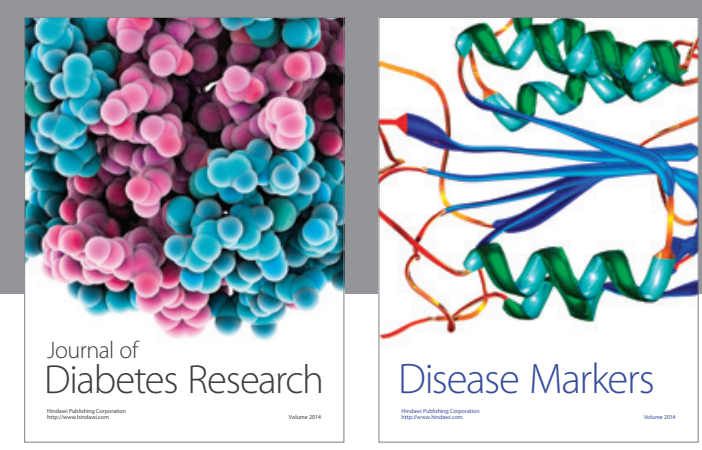

Disease Markers
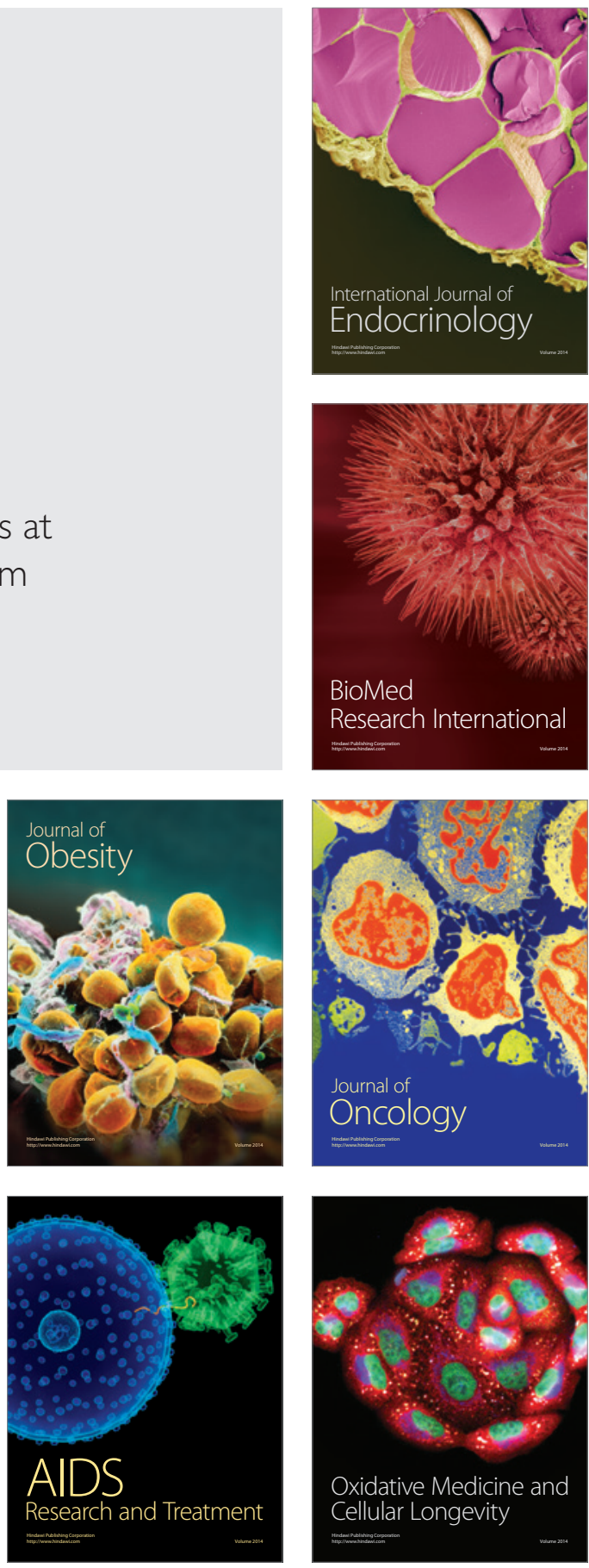